\title{
A semiautomação da legendagem em How to get away with muder: analisando possíveis efeitos no trabalho do tradutor
}

\author{
Érika Nogueira de Andrade Stupiello e Ana Clara Azedo Oliveira*
}

\section{Introdução}

Vivemos em uma era em que a produção e o intercâmbio de materiais textuais e imagens e comunicação oral entre falantes de diferentes línguas fazem parte do cotidiano de uma parcela crescente da sociedade, que cada vez mais recorre a programas audiovisuais para informações, entretenimento, educação e, até mesmo, comércio. A não muito tempo atrás, o fluxo de comunicação era unidirecional, do cinema ou da televisão para um público passivo. Na atualidade, pode-se dizer que esse trânsito é bidirecional: o consumidor contemporâneo, a par da tecnologia disponível, tem papel ativo na divulgação, distribuição e, em alguns casos, na tradução desses materiais disponíveis online.

As transformações promovidas pela globalização e a popularização da internet, que abriu novos ângulos para intercâmbios linguísticos, culturais e comerciais, são as grandes promotoras da tendência de "audiovisualização" da comunicação (Díaz-Cintas, 2015). No momento em que sons e imagens se unem, a mensagem torna-se mais atraente e sua disseminação em diferentes línguas é possibilitada pela tradução da comunicação oral em formato de legendas para rápida leitura e consequente interação do público.

A legenda, concebida como uma "interpretação condensada ou não das falas de um filme ou programa de televisão" (Araújo, 2006, p. 156) e

\footnotetext{
* Erika Nogueira de Andrade Stupiello é Professora Assistente Doutora do Departamento de Letras Modernas da Unesp, campus de São José do Rio Preto. Tradutora pública e intérprete comercial (inglês e português) desde 2000. Ana Clara Azedo Oliveira é Bacharela em Letras com Habilitação de Tradutor (Inglês) pela Unesp.
} 
como um meio de preservar "sons, vozes e desempenhos interpretativos do material audiovisual original" (Carvalho, 2005, p. 96), é considerada a maneira mais econômica e rápida de vencer a limitação da barreira linguística em produções estrangeiras.

Intercâmbios linguísticos promovidos pelo meio audiovisual e formalizados pelas legendas têm sido objeto de atenção de diversos estudos nos últimos anos, sejam eles de cunho descritivo (Díaz-Cintas, 1997; Sokoli, 2005, por exemplo) ou envolvendo aspectos específicos que impõem desafios ao trabalho do tradutor, como a tradução do humor (Fuentes Luque, 2000) ou de expressões idiomáticas (Gottlieb, 1997), por exemplo. Por outro lado, ainda são incipientes os estudos sobre o impacto da adoção das tecnologias de auxílio ao tradutor, especificamente os sistemas de memória de tradução, na tradução de legendas.

Sendo a internet considerada por estudiosos como Díaz-Cintas (2015, p. 633) "a grande catalisadora de mudanças na comunicação audiovisual e na tradução" e uma vez que nossa sociedade está cada vez mais "dependente de programas audiovisuais para informação, entretenimento, educação e comércio", o mercado de legendagem tende a oferecer oportunidades de trabalho para tradutores qualificados para produzir legendas de qualidade e dentro de prazos cada vez mais exíguos.

Considerando esse fato e procurando contribuir para o desenvolvimento dos estudos que associam a adoção de tecnologias na tradução audiovisual, este trabalho apresenta os resultados de uma pesquisa sobre a praticabilidade do uso de sistemas de memória de tradução para aumentar a eficiência, a padronização e a dinamização do trabalho de tradução de legendas por tradutores em formação.

A pesquisa envolveu a análise das traduções de legendas de quatro episódios da série de televisão norte-americana How to Get Away with Murder e foi desenvolvida com quatro estudantes, com faixa etária entre 21 e 22 anos, do quarto e último ano do curso de Bacharelado em Letras com Habilitação de Tradutor da Unesp de São José do Rio Preto. O objetivo foi investigar os efeitos da adoção de um sistema de memória de tradução no tempo de produção e na qualidade das legendas e a possível ocorrência de padronização de termos e frases recorrentes nos episódios selecionados para tradução. O 
sistema utilizado, Wordfast Classic (versão 6.38, a mais atual à época do estudo) foi escolhido devido à familiaridade dos participantes da pesquisa com essa ferramenta e o editor de textos Microsoft Word.

Para analisar as soluções adotadas pelos tradutores em formação, utilizamos, para fins de comparação, traduções feitas por legendadores profissionais, disponíveis no DVD oficial da série, e por tradutores amadores (fansubbers), disponíveis na internet pelo site TVsubtibles ${ }^{1}$. O exame proposto focou a padronização do discurso jurídico característico da série e analisou as semelhanças e diferenças entre as opções de tradução dos participantes do estudo e dos legendadores profissionais e amadores. Buscou-se, assim, determinar os efeitos da ferramenta na produção das traduções das legendas e de que maneira ela contribuiu para aprimorar as condições de trabalho dos estudantes participantes do estudo em relação à qualidade das legendas feitas por legendadores profissionais e amadores.

Aumento de produtividade e qualidade de trabalho constituem prérequisitos importantes para tradutores novatos e experientes inseridos no mercado contemporâneo. A descrição do acelerado ritmo de trabalho de tradutores que lidam com materiais em formato eletrônico pode ser exemplificada na prática de tradução de legendas para um mercado tão competitivo e extremamente atualizado como o audiovisual. Nos últimos anos, a legendagem de filmes, documentários, séries, vídeo games e outros programas audiovisuais aumentou de maneira significativa, não somente como uma maneira de vencer barreiras linguísticas, mas também como forma de conferir acessibilidade a pessoas surdas e ensurdecidas (Díaz-Cintas, 2012).

Demandas por rapidez de produção, realizada pelos menores custos possíveis pelo mercado de traduções implicam, necessariamente, em transformações no treinamento de tradutores para incluir o ensino de ferramentas de auxílio à tradução, em especial, nos programas universitários de formação desses profissionais. Autores como Gouadec (1994), Austermühl (2001), Bowker (2002), Pym (2003), Biau Gil e Pym (2006) e Martins (2006) têm afirmado em suas obras a necessidade da incorporação do ensino das novas tec-

\footnotetext{
${ }^{1}$ Disponível em: http://www.tvsubtitles.net. Acesso em 19 abr. 2017.
} 
nologias de auxílio à tradução nos currículos de cursos universitários de tradução, a fim de capacitar os tradutores graduados nesses cursos para vencerem os desafios e sobreviverem à concorrência do mercado contemporâneo de traduções. Mudanças no perfil do tradutor profissional impõem, segundo Pym (2003), uma redefinição de competência tradutória que, conforme defende, deve vir lado a lado com a capacidade de manipulação de vários tipos de programas de auxílio ao tradutor, entre eles, os sistemas de memória de tradução.

Analisar a maneira como o aprendiz de tradução se relaciona com as ferramentas (neste caso, os sistemas de memória) com as quais ele começa a aprender o ofício é relevante na medida em que a interação entre o tradutor e a ferramenta coloca-se como um fator decisivo na construção da imagem do futuro profissional que deseja atuar na área de tradução de materiais textuais em formato eletrônico.

Dado o fato de os sistemas de memória de tradução apresentarem melhor desempenho ao serem utilizados em traduções de textos especializados e com alto grau de repetições, pressupôs-se que essas ferramentas pudessem também ser aplicadas na produção tradutória de legendas de diferentes episódios de um seriado de TV, em que há recorrência frequente de jargões e terminologia específica. De acordo com Díaz-Cintas (2015, p. 642), "a chave do sucesso pode não estar na tecnologia em si, mas no uso inovador que a indústria e os legendadores fazem dela".

Não sendo os sistemas de memória parte da rotina atual de trabalho de legendadores profissionais e amadores, nosso estudo procurou explorar as possibilidades de aumento de produtividade e padronização que essa ferramenta pode oferecer, especialmente em trabalhos com frases, expressões e termos recorrentes, investigando os possíveis efeitos da semiautomação na produção final das legendas.

\section{Aplicação de sistema de memória de tradução em legendagem: uma proposta}

A literatura relacionada às tecnologias empregadas no trabalho de tradução, em especial no que se refere aos sistemas de memória, pouco discorre a respeito dessas ferramentas em um campo tão desenvolvido e constantemente 
atualizado como o audiovisual. A semiautomação do trabalho de tradução aplica-se majoritariamente a textos considerados de alto índice de repetições, como os de domínio especializado ou técnico. Tal condicionante parece explicar o fato de ainda serem incipientes os estudos sobre o impacto da adoção das tecnologias de auxílio ao tradutor na tradução de legendas (Rojas, 2014; Volk, 2008).

Dada a importância comercial da legendagem, para Díaz-Cintas (2015, p. 641) é intrigante que engenheiros de software ainda não tenham desenvolvido ferramentas que, além de incluírem corretores ortográficos, também poderiam auxiliar legendadores com a "dimensão linguística, e não apenas com tarefas técnicas" na produção de legendas. De acordo com o autor, avanços referentes ao aspecto linguístico na legendagem têm sido muito mais modestos, se comparados aos inúmeros avanços relacionados à dimensão técnica na legendagem, como programas que otimizam a marcação e o reconhecimento de voz, como, por exemplo, o VoxcribeCC ${ }^{2}$.

A adoção dessas ferramentas poderia, entre outros, ajudar a melhorar a coerência terminológica, "especialmente em traduções realizadas em equipe ou em séries de TV que possuem inúmeros episódios", facilitar a consulta e criação de glossários, incluir dicionários e "sugerir sinônimos respeitando as restrições de espaço", e, sobretudo, propor o "reaproveitamento (de trechos) de legendas que tenham sido previamente traduzidos a fim de dar conta de expressões iguais ou semelhantes" (Díaz-Cintas, 2015, p. 641).

Considerando a disseminação do uso de legendas na comunicação audiovisual, podemos afirmar que as perspectivas técnica e linguística merecem uma análise detalhada. Nesse sentido, propusemos analisar a aplicação do sistema de memória Wordfast Classic (versão 6.0b) ${ }^{3}$ como recurso de produtividade para tradutores em formação durante a execução das traduções das legendas de quatro episódios do seriado norte-americano How to get away with murder, um thriller jurídico que conta a história de uma proemi-

\footnotetext{
${ }^{2}$ Disponível em: https://dirtdirectory.org/resources/voxcribecc. Acesso em 19 abr. 2017.

${ }^{3}$ Disponível no link: https://www.wordfast.net/index.php? whichpage=downloadpage. Acesso em 19 abr. 2017.
} 
nente advogada de defesa e professora de Direito Penal e seu grupo de ambiciosos estudantes que, involuntariamente, se veem envolvidos em uma trama de assassinato.

A escolha de How to Get Away with Murder como objeto de análise deste estudo justifica-se por esse seriado apresentar uma narrativa fragmentada e entrelaçada por meio de flashforwards e flashbacks, um artifício usado pelo meio audiovisual de modo a interromper a sequência cronológica da história pela interpolação de eventos ocorridos posterior e anteriormente. Essas idas e vindas no tempo garantem a cada episódio um índice significativo de repetições, o que favorece o emprego de um sistema de memória de tradução, na medida em que essa ferramenta agiliza o trabalho do tradutor ao reaproveitar trechos de legendas previamente traduzidos a fim de dar conta da recorrência de diálogos iguais ou semelhantes.

Se adicionarmos o fato de que o enredo do seriado se concentra em aulas de direito criminal e casos que ilustram, na prática, toda a teoria abordada em sala de aula, podemos argumentar que o gênero da série constitui um tipo de texto propício ao emprego dos sistemas de memória em relação à uniformização da terminologia e fraseologia específicas do setor penal e jurídico e a otimização da qualidade da produção tradutória.

Para o desenvolvimento do corpus de pesquisa foram selecionados quatro episódios da primeira temporada de How to Get Away with Murder, de aproximadamente 43 minutos de duração cada. Os episódios escolhidos para compilação da tradução pelos quatro participantes da pesquisa, dois com e dois sem a assistência da ferramenta Wordfast, foram: o primeiro, "Piloto" (Pilot); o nono, "Me Mate, Me Mate, Me Mate" (Kill Me, Kill Me, Kill Me); o décimo, “Olá, Raskolnikov" (Hello Raskolnikov); e o décimo-quinto, "É Tudo Culpa Minha" (It's All My Fault). 
Cada um dos estudantes recebeu um documento em formato compatível com o Microsoft Word, contendo a transcrição completa e já sincronizada dos quatro episódios da série em seu idioma original, neste caso, o inglês. Esse arquivo corresponde às legendas ocultas (closed captions) dos episódios selecionados da primeira temporada de How to Get Away with Murder, disponíveis no site TVsubtitles.net. A Figura 1 ilustra o formato do arquivo entregue aos participantes:

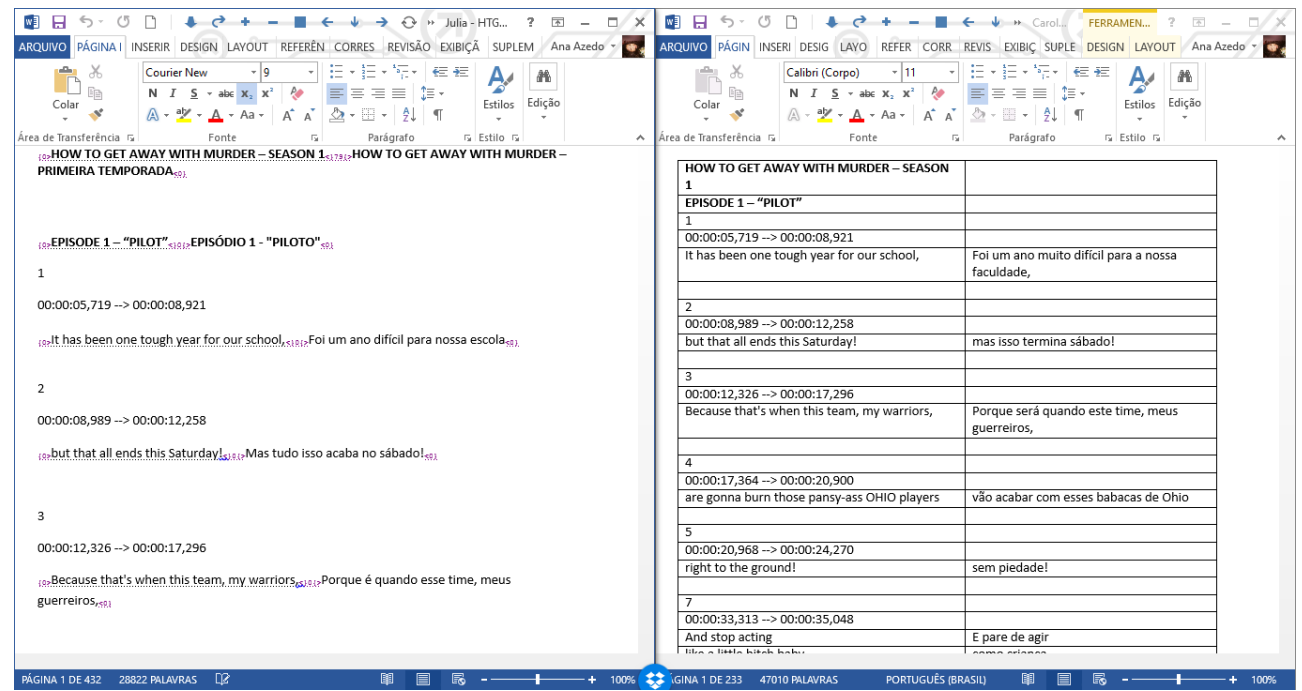

Figura 1 - Ilustração do documento de tradução entregue aos estudantes. À esquerda, tem-se a interface de uma tradução com a assistência do sistema de memória Wordfast, em que se pode distinguir os tags, em magenta, separando texto de origem e tradução. À direita, a interface do trabalho realizado sem o auxílio da ferramenta com a tabela bicolunada. Na imagem pode-se ver que o arquivo de texto entregue aos estudantes já está sincronizado.

Para seguir os padrões técnicos propostos pelo mercado de trabalho audiovisual em relação ao tamanho das legendas (Díaz-Cintas; Remael, 2007), foi estabelecido que as mesmas deveriam ter, no máximo, 32 a 35 caracteres por linha, sendo permitidos 37 caracteres em casos excepcionais. Cada participante foi instruído a registrar o tempo de produção de tradução de legendas de um episódio.

Ao final do trabalho, todos os estudantes da pesquisa foram instruídos a responder a um questionário com as seguintes perguntas: 
1. Quais os principais desafios encontrados na tradução das legendas?

2. Como foram resolvidas as dificuldades encontradas?

3. Quais recursos de pesquisa e tradução foram úteis na realização do trabalho?

Com base nas respostas de cada participante, foi possível orientar a análise das traduções realizadas e identificar os pontos específicos de atenção durante o processo de comparação dos trabalhos efetuados com e sem a adoção do Wordfast. Foram levados em consideração: a restrição de espaço, a uniformização da terminologia jurídica e a padrozinação dos trechos referentes às cenas repetidas em flashforward e flashback. Os estudantes que não utilizaram a tecnologia comentaram sobre a dificuldade de manter a coerência terminológica, quando não podiam contar com os recursos de segmentação e recuperação de correspondências textuais da ferramenta.

Os estudantes foram instruídos a criar uma nova memória de tradução de modo que a compilação das informações ao seu banco de dados não sofresse a influência de textos de outras áreas e se detivesse ao vocabulário jurídico e penal abordado pela história da série. Justamente pelo fato de os participantes terem iniciado o processo de legendagem com uma memória do "zero", ou seja, uma base de dados isenta de unidades de tradução, os participantes inicialmente não obtiveram ganhos expressivos de eficiência em relação ao reaproveitamento de informações pela adoção do sistema de memória Wordfast.

A explicação dessa ocorrência reside no fato de ser necessário um tempo considerável para que o tradutor consiga compilar uma quantidade significativa de unidades de tradução para começar a usufruir dos recursos de seu sistema de memória. Por isso, a tradução do primeiro episódio de How to Get Away with Murder não acusou a recuperação de nenhum trecho de legenda de interesse para esta pesquisa. Nesta etapa, os participantes afirmaram em seus questionários que a memória os poupou do exaustivo trabalho de digitação dos nomes das personagens, assim como de lugares e datas, os quais aparecem com certa frequência durante o episódio, na medida em que disponibilizou automaticamente ao tradutor-usuário a opção para tradução. 
Apesar de terem sido poucos os ganhos durante o processo de legendagem, a criação de legendas para o primeiro episódio foi essencial para a posterior ativação dos recursos de recuperação e correspondência textual, ainda que de modo parcial. Além de os tradutores terem compilado uma grande quantidade de unidades de tradução referentes a flashforwards e flashbacks, que viriam a se repetir nos episódios seguintes, eles também armazenaram termos e fraseologias específicas do setor penal e jurídico, jargão investigativo e criminal, garantindo maior consistência à produção tradutória dos próximos episódios.

De modo geral, a partir da tradução do nono episódio, mais trechos de legendas foram recuperados pela memória e reaproveitados pelos tradutores, aumentando, assim, a eficiência de seu trabalho.

Os trechos na Tabela 1 foram extraídos do episódio nove, que gerou um grande número de recorrências recuperadas pela memória de tradução referentes ao episódio piloto:

\begin{tabular}{|c|c|c|}
\hline \multirow[t]{2}{*}{350} & \multirow[t]{2}{*}{ 00:19:21,823 --> 0:19:23,591 } & $\begin{array}{c}\{0>\text { Stop acting }<\} 100\{> \\
\text { Para de agir }<0\}\end{array}$ \\
\hline & & $\begin{array}{c}\{0>\text { like a little bitch baby. }<\} 100\{> \\
\text { feito uma criança. }<0\}\end{array}$ \\
\hline 351 & 00:19:23,625--> 00:19:25,092 & $\begin{array}{c}\{0>\text { Don't tell me how to feel right now } !<\} 100\{> \\
\text { Não me diga como me sentir } !<0\}\end{array}$ \\
\hline 352 & $00: 19: 26,428$--> 00:19:28,261 & $\begin{array}{c}\{0>\text { Sorry it took so long. }<\} 100\{> \\
\text { Desculpe a demora. }<0\}\end{array}$ \\
\hline 353 & $00: 19: 28,295$--> 00:19:29,763 & $\begin{array}{l}\{0>\text { I went back for this }<\} 100\{> \\
\text { Eu voltei para pegar isso. }<0\}\end{array}$ \\
\hline 354 & 00:19:30,965 --> 00:19:33,066 & $\begin{array}{c}\{0>\text { You take that back right now } !<\} 83\{> \\
\text { Devolva isso agora } \mid<0\}\end{array}$ \\
\hline 355 & 00:19:33,101 --> 00:19:34,701 & $\begin{array}{c}\{0>\text { No. }<\} 100\{>\text { Não. }<0\} \\
\{0>\text { It's smart. }<\} 100\{> \\
\text { Isso é bom. }<0\} .\end{array}$ \\
\hline 356 & $00: 19: 34,736$--> 00:19:36,970 & $\begin{array}{c}\{0>\text { Commonwealthy v. Deloatche } \ldots<\} 100\{> \\
\text { Estado vs. Deloatche...<0\} }\end{array}$ \\
\hline
\end{tabular}




\begin{tabular}{|l|l|l|}
\hline 357 & $00: 19: 37,004->00: 19: 39,072$ & $\begin{array}{l}\{0>\text { A case the prosecution }<\} 100\{> \\
\text { Um caso que a acusação }<0\}\end{array}$ \\
\cline { 3 - 4 } & & $\begin{array}{r}\{0>\text { should've won but lost }<\} 100\{> \\
\text { devia ter ganhado mas perdeu }<0\}\end{array}$ \\
\hline 358 & $00: 19: 39,107->00: 19: 41,074$ & $\begin{array}{l}\{0>\text { because there was no murder } \\
\text { weapon }<\} 100\{>\end{array}$ \\
& & \begin{tabular}{l} 
werque não havia arma do crime. $<0\}$ \\
\hline
\end{tabular}
\end{tabular}

Tabela 1 - Trechos recuperados do nono episódio pela memória. A tabela divide-se em: número de legenda, tempo de duração de legenda e "texto sujo", arquivo que contém o texto original segmentado junto com a sua respectiva tradução, divididos pelos marcadores, denominados tags (em magenta), que indicam o grau de correspondência textual entre o novo segmento com um segmento contido no banco de dados da memória.

Conforme é possível verificar na Tabela 1, as legendas foram recuperadas pelo Wordfast com grau de similaridade entre $100 \%$ a $83 \%$, número que varia de 0 a 100, dependendo da semelhança entre os segmentos do original e da tradução. Pode-se dizer que o recurso de "correspondência textual" (matching) proporcionou maior agilidade à legendagem, na medida em que possibilitou que o tradutor-usuário economizasse tempo, por meio da recuperação de traduções já realizadas e salvas, e se dedicasse à tradução de segmentos ainda não traduzidos. É importante destacar que a recuperação não se limitou a legendas de cenas anteriormente apresentadas, mas, especialmente falas recorrentes do cotidiano (linhas 350 e 352), que podem ser padronizadas com o uso da memória, caracterizando ainda mais o jeito de falar de um personagem, por exemplo.

De modo geral, o episódio quinze obteve maior índice de recuperação de trechos de diálogos curtos e recorrentes. O Wordfast localizou correspondências exatas e, principalmente, parciais em segmentos formados por nomes das personagens, endereços, datas e horários, e perguntas e respostas triviais ou retóricas. Por exemplo, as unidades de tradução "She was pregnant" e "Sam killed Lila" foram recorrentes neste episódio e puderam ser reaproveitados para tradução de novos segmentos como os seguintes: “ $\underline{\text { Since }}$ 
Lila was pregnant," e "Sam killed Lila, okay?", os quais obtiveram um índice de similaridade superior a $75 \%$.

A determinação dos ganhos de produtividade proporcionados pela aplicação da ferramenta é apresentada na Tabela 2 a seguir, que distribui o tempo que os participantes do estudo levaram para traduzir as legendas dos episódios do estudo:

\begin{tabular}{l|r|r|r|r} 
& $\begin{array}{c}\text { Tradutor 1 } \\
\text { WORDFAST }\end{array}$ & \multicolumn{1}{c}{ Tradutor 2 } & \multicolumn{1}{c}{ Tradutor 3 } & Tradutor 4 \\
\hline EORDFAST & & \\
\hline Episódio 1 & $4 \mathrm{~h} 40$ & $5 \mathrm{~h} 10$ & $4 \mathrm{~h} 38$ & $4 \mathrm{~h} 50$ \\
\hline Episódio 9 & $2 \mathrm{~h} 30$ & $3 \mathrm{~h} 30$ & $4 \mathrm{~h} 20$ & $3 \mathrm{~h} 30$ \\
\hline Episódio 10 & $3 \mathrm{~h} 50$ & $4 \mathrm{~h}$ & $4 \mathrm{~h} 12$ & $4 \mathrm{~h}$ \\
\hline Episódio 15 & $4 \mathrm{~h} 25$ & $4 \mathrm{~h} 15$ & $4 \mathrm{~h} 30$ & $5 \mathrm{~h} 50$ \\
\cline { 2 - 5 } & & & &
\end{tabular}

Tabela 2 - Tempo de legendagem por episódio. Na vertical, as duas colunas "Tradutor 1" e "Tradutor 2" apresentam os tempos de tradução dos episódios (na horizontal) com assistência do Wordfast. Já nas colunas "Tradutor 3" e "Tradutor $4^{\prime \prime}$, os tempos de tradução necessário aos participantes que realizaram o trabalho sem o auxílio da ferramenta. Os estudantes foram instruídos a marcarem o tempo de início e de término da tradução de cada episódio.

De acordo com os valores expressos na Tabela 2, no geral, não houve uma diferença significativa entre os tempos de legendagem com e sem o auxílio do programa Wordfast Classic. Entretanto, conforme informado nos questionários, os participantes 3 e 4 tiveram de dispor de três horas adicionais para revisar todo conteúdo dos episódios, o que corresponderia 45 minutos a mais do tempo gasto para finalização do trabalho de tradução de cada episódio.

Para uma análise mais pontual sobre o efeito da adoção do sistema de memória de tradução Wordfast Classic na produção e na padronização da terminologia jurídica das legendas, selecionamos treze termos recorrentes nos quatro episódios e de grande ocorrência em audiências públicas. Com 
base nessa amostra, apresentamos uma análise estatística da ocorrência desses termos nos episódios com o objetivo de observar como tais termos foram traduzidos em cada caso. Os resultados são apresentados na Tabela 3.

\begin{tabular}{|c|c|c|c|c|c|c|c|}
\hline TERMO & Ocorrências & $\begin{array}{l}\text { Tradutor l } \\
\text { com WF }\end{array}$ & $\begin{array}{l}\text { Tradutor } 2 \\
\text { com WF }\end{array}$ & $\begin{array}{l}\text { Tradutor } \\
\text { sem WF }\end{array}$ & $\begin{array}{l}\text { Tradutor } \\
\text { sem WF }\end{array}$ & Fansubbers & $\begin{array}{c}\text { Legenda } \\
\text { oficial }\end{array}$ \\
\hline Actus reus & 2 & $\begin{array}{l}\text { Actus reus; } \\
\text { ato de culpa }\end{array}$ & $\begin{array}{l}\text { Actus réus; } \\
\text { culpado }\end{array}$ & $\begin{array}{l}\text { Actus reus; ato } \\
\text { culposo }\end{array}$ & $\begin{array}{l}\text { Actus reus; ato } \\
\text { de culpa }\end{array}$ & $\begin{array}{l}\text { Actus reus; ato } \\
\text { criminal }\end{array}$ & $\begin{array}{c}\text { Ato } \\
\text { criminoso }\end{array}$ \\
\hline $\begin{array}{l}\text { Attempted } \\
\text { murder }\end{array}$ & 3 & $\begin{array}{l}\text { Tentativa de } \\
\text { homicídio }\end{array}$ & $\begin{array}{l}\text { Tentativa de } \\
\text { homicidio }\end{array}$ & $\begin{array}{l}\text { Tentativa de } \\
\text { homicídio; } \\
\text { homicídio }\end{array}$ & $\begin{array}{l}\text { Tentativa de } \\
\text { homicidio; } \\
\text { tentativa de } \\
\text { assassinato }\end{array}$ & $\begin{array}{c}\text { Tentativa de } \\
\text { assassinato; } \\
\text { tentativa de } \\
\text { homicídio }\end{array}$ & $\begin{array}{l}\text { Tentativa de } \\
\text { homicidio }\end{array}$ \\
\hline $\begin{array}{c}\text { Commonwealth } \\
\text { v. }\end{array}$ & 3 & Estado vs. & Estado vs. & Povo vs. & $\begin{array}{c}\text { Commonwealth } \\
\text { vs. }\end{array}$ & $\begin{array}{c}\text { Povo vs.; } \\
\text { Commonwealth } \\
\text { vs. }\end{array}$ & $\begin{array}{l}\text { Estado vs. } \\
\text { Estado } \\
\text { contra; } \\
\text { Povo contra; }\end{array}$ \\
\hline Conviction & 3 & Condenação & $\begin{array}{l}\text { Condenação; } \\
\text { convicção }\end{array}$ & $\begin{array}{l}\text { Condenação; } \\
\text { condenação } \\
\text { criminal }\end{array}$ & $\begin{array}{l}\text { Condenaçãa; } \\
\text { condenação } \\
\text { criminal }\end{array}$ & Condenação & Condenação \\
\hline $\begin{array}{l}\text { Defense } \\
\text { attorney }\end{array}$ & 2 & $\begin{array}{l}\text { Advogado } \\
\text { de defesa; } \\
\text { advogado }\end{array}$ & $\begin{array}{l}\text { Advogado } \\
\text { de defesa; } \\
\text { advogado }\end{array}$ & $\begin{array}{l}\text { Advogado de } \\
\text { defesa; } \\
\text { advogado }\end{array}$ & Advogado & Advogado & $\begin{array}{l}\text { Advogado de } \\
\text { defesa; } \\
\text { advogado }\end{array}$ \\
\hline Detective & 14 & Detetive & Detetive & Detetive & Detetive & Detetive & $\begin{array}{l}\text { Investigador; } \\
\text { policial; } \\
\text { detetive }\end{array}$ \\
\hline Discovery file & 3 & Provas & Provas & $\begin{array}{l}\text { Arquivo; } \\
\text { provas }\end{array}$ & Provas & Arquivos & $\begin{array}{c}\text { Lista de } \\
\text { provas }\end{array}$ \\
\hline Evidence & 10 & Evidência & Evidência & $\begin{array}{l}\text { Evidência; } \\
\text { prova }\end{array}$ & Evidência & Evidência & Prova \\
\hline Forensics & 2 & Legistas & Forenses & $\begin{array}{l}\text { Criminalistica; } \\
\text { legistas }\end{array}$ & Peritos; legistas & $\begin{array}{c}\text { Cientistas } \\
\text { forense; peritos }\end{array}$ & Legistas \\
\hline Intent & 2 & Intenção & Intenção & Dolo & Intenção & Dolo; intenção & Intenção \\
\hline Murder & 28 & $\begin{array}{l}\text { Assassinato; } \\
\text { homicídio }\end{array}$ & $\begin{array}{l}\text { Assassinato; } \\
\text { homicídio }\end{array}$ & $\begin{array}{l}\text { Assassinato; } \\
\text { homicidio }\end{array}$ & $\begin{array}{l}\text { Assassinato; } \\
\text { homicídio }\end{array}$ & $\begin{array}{l}\text { Assassinato; } \\
\text { homicídio }\end{array}$ & $\begin{array}{l}\text { Assassinato; } \\
\text { homicídio }\end{array}$ \\
\hline Prosecution & 4 & Acusação & Processo & Promotoria & Promotoria & Promotoria & $\begin{array}{l}\text { Acusação; } \\
\text { Promotoria }\end{array}$ \\
\hline To testify & 4 & Testemunhar & Testemunhar & $\begin{array}{l}\text { Testemunhar; } \\
\text { depor }\end{array}$ & Testemunhar & Testemunhar & $\begin{array}{l}\text { Testemunhar; } \\
\text { depor }\end{array}$ \\
\hline
\end{tabular}

Tabela 3 - As opções tradutórias nas diversas ocorrências da terminologia jurídica.

De acordo com a Tabela 3, podemos concluir que os participantes do estudo que utilizaram a ferramenta Wordfast para tradução dos episódios mantiveram, na maior parte das vezes, as mesmas escolhas terminológicas durante todo o processo tradutório, garantindo maior consistência e qualidade ao seu trabalho final, como os termos "Evidence" e "Muder"

Já os participantes que não contaram com a assistência da memória para criação de legendas - além dos legendadores profissionais, responsáveis pela legenda oficial do DVD, e dos tradutores amadores - não mantiveram a mesma padronização terminológa, variando suas escolhas na tradução de um termo com mais de uma ocorrência, como em "Commonwealth v." e "Detective". 
A diferença de uniformização entre os termos apresentados também é apresentada no Gráfico 1.

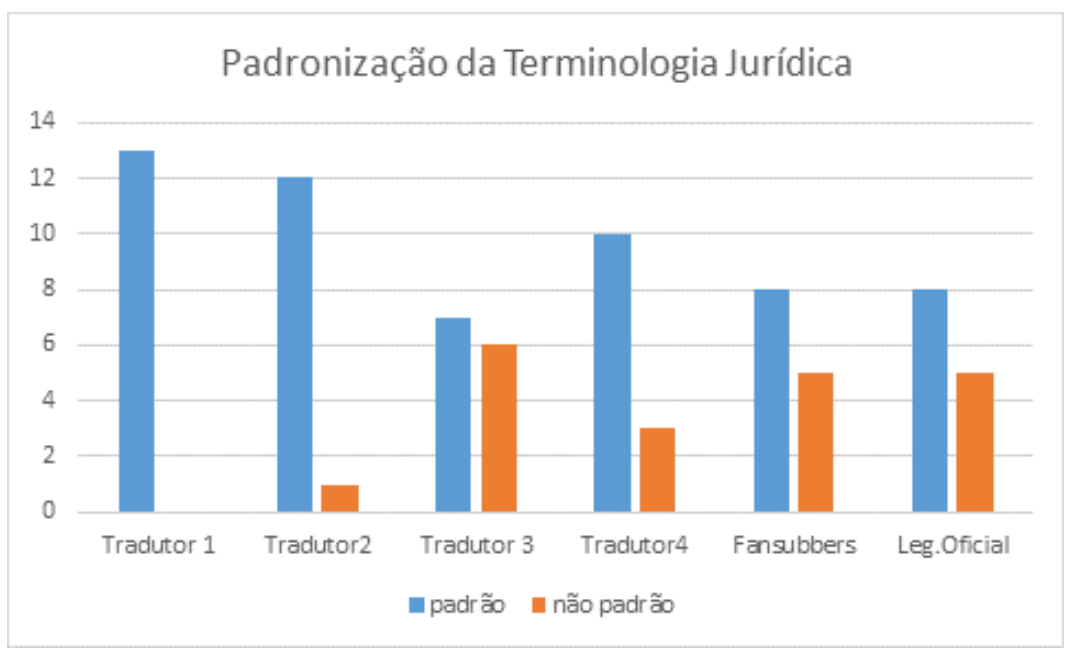

Gráfico 1 - Nível de padronização da terminologia jurídica.

Pelas diferenças entre as colunas em azul e laranja, notamos que o Tradutor 1 manteve as mesmas opções nas traduções dos treze termos estudados em todos os episódios. Na representação das opções do Tradutor 2, observamos uma variação na tradução em apenas um dos termos ("Convinction") nos episódios. Já no caso dos Tradutores 3 e 4, dos fansubbers e do legendador oficial, constatamos que a variação terminológica foi significativa, sendo representada pela coluna em laranja.

Com base nos dados apresentado, concluímos que o uso de um sistema de memória na prática da legendagem pode contribuir para o "senso de continuidade" dos episódios, amarrando-os linguisticamente de modo a facilitar a lembrança e a compreensão do telespectador.

A padronização terminológica dos trechos em flashback e flashforward, recuperados pela memória, também foi avaliada no trabalho de legendagem profissional e dos fãs. A tabela a seguir apresenta a tradução do trecho de uma mesma cena em flashforward, encontrada nos episódios um e nove da 
série, realizada pelos estudantes com o auxílio do Wordfast, que usaram exatamente a mesma equivalência para os trechos da legenda original (coluna 1) e pelo legendador profissional (coluna 2 e 3 ).

\begin{tabular}{|c|c|c|}
\hline Legenda - WORDFAST & \multicolumn{2}{|c|}{ Legenda - DVD } \\
\hline Episódio 1/9 & Episódio 1 & Episódio 9 \\
\hline Pare de agir feito uma criança. & \multirow{2}{*}{$\begin{array}{c}\text {-Pare de agir feito criança. } \\
\text {-Não me diga o que sentir agora! }\end{array}$} & \multirow{2}{*}{$\begin{array}{l}\text {-Pare de agir feito um bebê. } \\
\text {-Não me diga como sentir! }\end{array}$} \\
\hline Não me diga como me sentir! & & \\
\hline $\begin{array}{c}\text { Desculpe a demora. } \\
\text { Eu voltei para pegar isso. }\end{array}$ & $\begin{array}{l}\text { Desculpe a demora. } \\
\text { Fui buscar isto. }\end{array}$ & $\begin{array}{l}\text { Desculpem a demora. } \\
\text { Voltei [sic] pegar isto. }\end{array}$ \\
\hline Devolva isso agora! & Leve isso de volta agora! & $\begin{array}{l}\text {-Devolva agora mesmo! } \\
\text {-Não, foi inteligente. }\end{array}$ \\
\hline $\begin{array}{l}\text { Não. Isso é bom. } \\
\text { Estado vs. Deloatche... }\end{array}$ & $\begin{array}{l}\text { Não, ele foi inteligente. } \\
\text { Estado } x \text { Loach. }\end{array}$ & $\begin{array}{l}\text { O Povo contra Deloatche. } \\
\text { A Promotoria perdeu o caso... }\end{array}$ \\
\hline $\begin{array}{c}\text { A acusação perdeu o caso } \\
\text { porque não havia arma do crime. }\end{array}$ & $\begin{array}{l}\text { A acusação perdeu o caso } \\
\text { pela ausência da arma. }\end{array}$ & $\begin{array}{l}\text {-pois não tinha arma do crime. } \\
\text {-O que quer dizer? }\end{array}$ \\
\hline $\begin{array}{l}\text {-O que está querendo dizer? } \\
\text {-Vamos limpar e devolver. }\end{array}$ & $\begin{array}{l}\text {-O que está dizendo? } \\
\text {-Vamos recolocar no lugar. }\end{array}$ & \multirow{2}{*}{$\begin{array}{l}\text { Limpamos e devolvemos. } \\
\text { Escondemos à vista de todos. }\end{array}$} \\
\hline Esconder à vista de todos. & Esconder à vista de todos. & \\
\hline $\begin{array}{l}\text { Depois de enterrarmos o corpo. } \\
\text { Não. Definitivamente, não! }\end{array}$ & $\begin{array}{l}\text {-Depois de enterrar o corpo. } \\
\text {-Não! De jeito nenhum! }\end{array}$ & $\begin{array}{l}\text {-Depois de enterrarmos o corpo. } \\
\text {-Não. De jeito nenhum. }\end{array}$ \\
\hline $\begin{array}{l}\text {-Estou com a Michaela. } \\
\text {-Não, Connor, pense. }\end{array}$ & $\begin{array}{l}\text {-Concordo com Michaela. } \\
\text {-Não, Connor. Pense. }\end{array}$ & $\begin{array}{c}\text {-Não, concordo com ela. } \\
\text {-Connor, pense. }\end{array}$ \\
\hline $\begin{array}{c}\text { Precisamos do troféu. } \\
\text { Mas o corpo fica onde está. }\end{array}$ & $\begin{array}{c}\text { Precisamos do troféu, } \\
\text { mas o corpo fica onde está }\end{array}$ & $\begin{array}{l}\text { O troféu, precisamos sim. } \\
\text { Mas o corpo fica onde está. }\end{array}$ \\
\hline Não, o corpo vai nos dedurar. & Com o corpo, vamos ser pegos. & \multirow{2}{*}{$\begin{array}{l}\text {-E o corpo que nos incrimina! } \\
\text {-Não está pensando direito. }\end{array}$} \\
\hline -Você não está pensando direito. & \multirow{2}{*}{$\begin{array}{l}\text {-Você não está pensando direito. } \\
\text {-O que você sugere? }\end{array}$} & \\
\hline$-\mathrm{O}$ que você sugere? & & \multirow{2}{*}{$\begin{array}{l}\text {-O que você sugere? } \\
\text {-Algo que não envolva... }\end{array}$} \\
\hline Algo que não envolva & \multirow{2}{*}{$\begin{array}{l}\text { Nada que envolva carregar } \\
\text { um corpo no campus... }\end{array}$} & \\
\hline carregar um corpo pelo campus & & \multirow{2}{*}{$\begin{array}{l}\text { levar um cadáver pelo campus } \\
\text { na noite mais cheia do ano! }\end{array}$} \\
\hline na noite mais agitada do ano! & na noite mais movimentado do ano. & \\
\hline Ela está certa, Laurel. & \multirow{2}{*}{$\begin{array}{c}\text { Mesmo que dê para tirar } \\
\text { o corpo da casa... }\end{array}$} & \multirow{2}{*}{$\begin{array}{l}\text { Pois é, mesmo que o tiremos } \\
\text { da casa sem sermos vistos... }\end{array}$} \\
\hline Mesmo saindo sem sermos vistos, & & \\
\hline Q chão está congelado! & \multirow{2}{*}{$\begin{array}{l}\text { - o chão está congelado! } \\
\text {-Temos a noite toda para cavar. }\end{array}$} & \multirow{2}{*}{$\begin{array}{l}\text { - o chão está congelado! } \\
\text {-Temos toda noite para cavar! }\end{array}$} \\
\hline -Temos a noite toda para cavar. & & \\
\hline Não sabe do que está falando! & \multirow{2}{*}{$\begin{array}{c}\text { Você não sabe o que diz! } \\
\text { E assassinato! } \\
\text { Ninguém aqui sabe o que diz. }\end{array}$} & \multirow{2}{*}{$\begin{array}{l}\text {-Não sabe do que está falando! } \\
\text {-Isto é crime! Ninguém sabe! }\end{array}$} \\
\hline $\begin{array}{l}\text { Isso é assassinato! } \\
\text { Ninguém sabe do que está falan }\end{array}$ & & \\
\hline
\end{tabular}

Tabela 4 - Comparação entre as legendas produzidas pelos estudantes para o mesmo trecho, exibido nos episódios 1 e 9, e aquelas exibidas no DVD da série.

Considerando apenas as traduções compiladas para o DVD da série, pode-se verificar que as legendas para os episódios um e nove se distinguem em dois níveis: técnico e linguístico. O domínio técnico refere-se à dimensão 
e à divisão dos caracteres por linhas de legenda, segundo o padrão estabelecido pelo mercado do número de palavras lidas por minuto, que é de 160 a 180 palavras (Díaz-Cintas; Remael, 2007). Já o nível linguístico envolve todas as modificações terminológicas e fraseológicas que as opções tradutórias feitas para o primeiro episódio sofreram em relação a tradução dos mesmos termos e frases no episódio nove.

Quanto à dimensão técnica, pode-se constatar que as legendas do primeiro episódio tiveram uma modificação em relação à quebra das linhas das legendas; em outras palavras, houve a divisão de duas linhas de texto e/ou a soma de uma linha com outra de legenda. A justificativa para essas diferenças pode residir no fato de ter sido realizada outra sincronização dos tempos de entrada e saída das legendas para o nono episódio, o que, consequentemente, afetou na disposição do texto na tela. Mais especificamente, verificase que as legendas do capítulo nove são mais extensas e explicativas se comparadas as legendas compiladas para o episódio piloto, aparecendo sempre em duas linhas.

Em contrapartida, as maiores e mais evidentes discrepâncias entre os dois episódios ocorreram na dimensão linguística. Todas as legendas do primeiro episódio se comparadas com as do episódio nove, se diferenciaram em, pelo menos, um de seus elementos. Essa variação incidiu sobre a grafia, a pontuação, a flexão verbal e até tradução de termos técnicos. Por exemplo, a frase "Estado x Loach" foi substituída por "O Povo contra Deloatche", e os termos "acusação", "corpo" e "assassinato" foram substituídos, respectivamente, por "Promotoria", "cadáver" e "crime". As legendas também diferem na omissão de algumas palavras dêiticas. Mais especificamente, a frase "She's right, Laurel" presente no áudio original e na tradução dos estudantes, foi suprimida, provavelmente, por questão da restrição de tempo em tela.

Para grandes entusiastas de produtos audiovisuais, que têm o hábito de fazer maratonas de seus seriados favoritos, ou seja, assistir todos os episódios de uma temporada em pouco tempo, um seguido do outro, a padronização entre as legendas é fundamental, uma vez que a diferença entre os textos pode ser identificada mais facilmente. Essa diferença talvez fosse de menor importância há algum tempo, uma vez que os episódios demoravam mais para serem divulgados e não contavam com o uso da internet para sua 
disseminação. Atualmente, além de as produções estarem disponíveis na rede logo após sua exibição na televisão, o público parece estar mais exigente, sempre em busca traduções de maior qualidade em prazos cada vez mais exíguos.

Diferentemente da legendagem profissional, a legendagem amadora, produzida pelos fãs da série, revelou uma maior uniformização entre os textos correspondentes à mesma cena anterior em relação às legendas do DVD.

\begin{tabular}{|c|c|}
\hline Legenda - WORDFAST & Legenda - MANIACSUBS \\
\hline Episódio 1/9 & Episódio1/9 \\
\hline Pare de agir feito uma criança. & $\begin{array}{c}\text { E pare de agir } \\
\text { seme uma criança. }\end{array}$ \\
\hline Não me diga como me sentir! & $\begin{array}{c}\text { Não me diga } \\
\text { some me sentir agora. }\end{array}$ \\
\hline \multirow[t]{2}{*}{$\begin{array}{c}\text { Desculpe a demora. } \\
\text { Eu voltei para pegar isso. }\end{array}$} & $\begin{array}{c}\text { Desculpe } \\
\text { por ter demorado. }\end{array}$ \\
\hline & Voltei para pegar isto. \\
\hline Devolva isso agora! & $\begin{array}{c}\text { Coloque isso de volta } \\
\text { agora. }\end{array}$ \\
\hline \multirow{2}{*}{$\begin{array}{c}\text { Não. Isso é bom. } \\
\text { Estado vs. Deloatche... }\end{array}$} & Não. E inteligente. \\
\hline & Povo vs. Deloatche. \\
\hline \multirow[t]{2}{*}{$\begin{array}{l}\text { A acusação perdeu o caso } \\
\text { porque não havia arma do crime. }\end{array}$} & $\begin{array}{c}\text { A Promotoria teria ganho, } \\
\text { mas perdeu }\end{array}$ \\
\hline & $\begin{array}{l}\text { pergue não tinha } \\
\text { arma do crime. }\end{array}$ \\
\hline $\begin{array}{l}\text {-O que está querendo dizer? } \\
\text {-Vamos limpar e devolver. }\end{array}$ & $\begin{array}{c}\text {-Quer dizer... } \\
\text {-Limpamos e devolvemos. }\end{array}$ \\
\hline $\begin{array}{c}\text { Esconder à vista de todos. } \\
\text { Depois de enterrarmos o corpo. }\end{array}$ & Escondido bem à vista. \\
\hline Não. Definitivamente, não! & $\begin{array}{l}\text {-Depois enterramos o corpo. } \\
\text {-Não, claro que não. }\end{array}$ \\
\hline $\begin{array}{l}\text {-Estou com a Michaela. } \\
\text {-Não, Connor, pense. }\end{array}$ & $\begin{array}{l}\text {-E, concordo com Michaela } \\
\text {-Não, Connor. Pense. }\end{array}$ \\
\hline $\begin{array}{c}\text { Precisamos do troféu. } \\
\text { Mas o corpo fica onde está. }\end{array}$ & $\begin{array}{c}\text { O troféu, tudo bem. } \\
\text { Mas o corpo fica onde está. }\end{array}$ \\
\hline Não, o corpo vai nos dedurar. & O corpo nos entregará. \\
\hline $\begin{array}{l}\text {-Você não está pensando direito. } \\
\text {-O que você sugere? }\end{array}$ & $\begin{array}{c}\text {-Não está pensando. } \\
\text {-O que sugere? }\end{array}$ \\
\hline $\begin{array}{l}\text { Algo que não envolva } \\
\text { carregar um corpo pelo campus }\end{array}$ & \multirow[t]{2}{*}{$\begin{array}{l}\text { Não carregar um corpo por aí } \\
\text { na noite mais cheia do ano. }\end{array}$} \\
\hline na noite mais agitada do ano! & \\
\hline Ela está certa, Laurel. & $\begin{array}{c}\text {-Ela está certa. } \\
\text {-Mesmo saindo sem nos verem, }\end{array}$ \\
\hline $\begin{array}{l}\text { Mesmo saindo sem sermos vistos, } \\
\text { \& chão está congelado! }\end{array}$ & \multirow[t]{2}{*}{$\begin{array}{l}\text {-o chão está congelado! } \\
\text {-Tem a noite toda para cavar. }\end{array}$} \\
\hline Temos a noite toda para cavar. & \\
\hline Não sabe do que está falando! & $\begin{array}{c}\text {-Não sabe o que fala. } \\
\text {-E um homicídio. Ninguém sabe! }\end{array}$ \\
\hline $\begin{array}{c}\text { Isso é assassinato! } \\
\text { Ninguém sabe do que está falando. }\end{array}$ & \\
\hline
\end{tabular}


A transcrição da produção de legendas da comunidade ManiacSubs é apresentada na Tabela 5 a seguir.

Tabela 5 - Comparação entre as legendas produzidas pelos estudantes com auxílio da ferramenta Wordfast e as legendas produzidas pelos fãs.

De acordo com uma mensagem trocada com a equipe ManiacSubs durante a pesquisa, os fãs relataram que, pelo fato de a tradução de cada episódio de How to Get Away with Murder ser produzida por mais de um integrante da equipe para agilizar o processo de tradução e disponibilização do material na rede, a qualidade de todo o trabalho só é garantida graças à um "método rudimentar de memórias de tradução". Esse método seria constituído por uma espécie de glossário em formato de planilha, atualizada a cada tradução de um novo capítulo e utilizado para busca de termos, frases ou cenas que sofrem repetição.

Outro fator a ser analisado na legendagem amadora, além do comprometimento com a padronização terminológica e a consistência do material, é o aspecto técnico empregado na dimensão e divisão dos caracteres na tela. Como já mencionado, os fãs, por estarem mais preocupados com a elaboração de uma tradução mais detalhada do conteúdo audiovisual, acabam por compilar legendas extensas, com mais informações do que o recomendado pela literatura sobre legendagem (Díaz-Cintas; Remael, 2007), o que pode vir a dificultar o tempo de leitura das legendas pelos telespectadores.

Podemos concluir que, nos episódios analisados, os participantes do estudo otimizaram a consistência e a qualidade do resultado final de suas legendas com o uso da memória de tradução Wordfast Classic em seu trabalho. Os recursos de segmentação, correspondência e recuperação textual do sistema Wordfast agilizaram o trabalho dos estudantes usuários dessa ferramenta ao possibilitar a reutilização de suas opções de tradução, resultando em um trabalho mais coeso e, possivelmente, de mais rápida associação para o telespectador. 


\section{Considerações finais}

Este estudo procurou dar os passos iniciais na investigação sobre a aplicação de sistemas de memória de tradução para traduzir legendas. Possíveis encaminhamentos desta pesquisa poderiam envolver a análise da produção de legendas auxiliadas por outros sistemas de memória (como o Wordfast Anywhere ou o MemoQ), ou, ainda, a aplicação dessa ferramenta em traduções colaborativas de séries de TV, que, frequentemente, empregam diversos tradutores-legendadores em episódios diferentes ou na renovação da temporada desses programas.

Os resultados desta pesquisa indicam que a composição das legendas, por representar diálogos constituídos por segmentos curtos de, no máximo, duas linhas, facilitou a aplicabilidade das funções de segmentação e correspondência textual do sistema de memória. Esses recursos possibilitaram maior produtividade e agilidade para a prática tradutória por aumentar as chances de a ferramenta reconhecer equivalências parciais e exatas, ao mesmo tempo conferindo maior padronização e consistência terminológica e fraseológica entre os episódios.

Conhecer as possibilidades e os limites da semiautomação no trabalho de legendagem pode ser útil para valorizar o trabalho humano, componente essencial de toda tradução, na medida em que libera o tradutor de tarefas repetitivas, possibilitando-lhe atuar na construção do sentido que a legenda terá para o público final.

\section{Agradecimentos}

Agradecemos à Fundação de Amparo à Pesquisa do Estado de São Paulo pelo financiamento desta pesquisa (FAPESP Processo no. 2015/11200-6). Somos gratas também pelas considerações e contribuições apresentadas pelos pareceristas deste número especial.

\section{Referências bibliográficas}

ARAÚJO, Vera Lúcia Santiago. “O processo de legendagem no Brasil”. Revista do GELNE, Fortaleza, v. 1/2, n. 1, p. 156-159, 2006. 
AUSTERMÜHL, Frank. Electronic tools for translators. Manchester: St. Jerome, 2001.

BIAU GIL, José Ramón; PYM, Anthony. “Technology and translation (a pedagogical overview)". In: Pym, A., Perekrestenko, A., Starink, B. (eds.), Translation technology and its teaching. Tarragona, Espanha, 2006. Disponível em: http://isg.urv.es/publicity/isg/publications/technology_2006/index.htm (acesso em 22 de janeiro de 2015).

BOWKER, Lynn. Computer-aided translation: a practical introduction. Ottawa: Ottawa University Press, 2002.

CARVALHO, Carolina Alfaro de. A tradução para legendas: dos polissistemas à singularidade do tradutor. Dissertação de Mestrado, Departamento de Letras, Pontifícia Universidade Católica do Rio de Janeiro, Rio de Janeiro, 2005.

DÍAZ-CINTAS, Jorge. "Subtitling: theory, practice and research". In: Millán, C.; Bartrina, F. (eds.), The Routledge Handbook of Translation Studies. London: Routledge, p. 273-287, 2012.

DÍAZ-CINTAS, Jorge. “Technological strides in subtitling”. In: Chan, S.W. (ed.), Routledge Encyclopedia of Translation Technology. London: Routledge, p. 632-643, 2015.

DÍAZ-CINTAS, Jorge. Subtitling as a mode of film translation within a Translation Studies framework - Manhattan Murder Mysteries, Woody Allen. Tese de Doutorado, Universitat de València, València, 1997.

DÍAZ-CINTAS, Jorge; REMAEL, Aline. Audiovisual Translation: Subtitling. Manchester, UK; Kinderhook, NY: St. Jerome Publishing, 2007.

FUENTES LUQUE, Adrián. La recepción del humor audiovisual traducido: studio comparative de fragmentos de las versiones doblada y subtitulada al español de la película Duck Soup, de los Hermanos Marx. Tese de Doutorado. Universidad de Granada, Granada, 2000.

GOTTLIEB, Henrik. Subtitles, Translation and Idioms. Tese de Doutorado. University of Copenhagen Centre for Translation Studies and Lexicography, Copenhagen, 1997.

GOUADEC, Daniel. “Traduction et Informatique: les implications pour la formation". Langages, 116, p. 59-74, 1994.

HOW TO GET AWAY WITH MURDER [DVD]. Estados Unidos: Walt Disney (Sonopress). 2014. 4 DVDs. 
PYM, Anthony. "Translational Ethics and Electronic Technologies". Anais do VI Seminário de Tradução Científica e Técnica em Língua Portuguesa A Profissionalização do Tradutor. Fundação Calouste Gulbenkian, Lisboa, 11 de novembro de 2003. Disponível em:

http://usuaris.tinet.cat/apym/on-line/translation/lisbon_ethics.pdf (acesso em 12 de fevereiro de 2015)

ROJAS, Katherin Pérez. "Automatically building translation memories for subtitling". In: Torressimon, E.; Orrego-Carmona, D. (eds.), Translation Research Projects 5. Tarragona: Intercultural Studies Group, p. 51-62, 2014.

SOKOLI, Stavroula. “Temas de investigación em traducción audiovisual: la definición del texto audiovisual". In: Zabalbeascoa, P.; Santamatia, L.; Chaume, F. (eds.), La Traduccion Audiovisual: Investigación, Enseñanza Y Profesión. Granada: Editorial Comares, p. 177-185, 2005.

TVSUBTITLES. Disponível em:

http://www.tvsubtitles.net/ (acesso em 15 de março de 2015)

VOLK, Martin. "The automatic translation of film subtitles: a machine translation success story?" Disponível em:

http://www.uzh.ch/news/articles/2008/3000/Volk_MT_of_Subtitles.pdf. (acesso em 20 de fevereiro de 2015).

WORDFAST: a universal and open translation tool. Disponível em: http://www.wordfast.net (acesso em 10 maio de 2015)

\section{Resumo}

Este trabalho investiga os possíveis efeitos da aplicação de um sistema de memória na tradução de textos de legendas, especificamente naquelas produzidas para o seriado How to Get Away with Murder. Com base no exame do trabalho de legendagem de quatro tradutores em formação com assistência ou não do sistema Wordfast Classic, e a comparação às legendas feitas por tradutores oficiais e amadores da série, analisamos de que maneira 
a semiautomação do trabalho de legendagem pode influenciar na uniformização e na aceleração do trabalho do tradutor.

\begin{abstract}
This study investigates the possible effects of using a translation memory system in the translation of subtitles, specifically those produced for the TV series How to Get Away with Murder. Based on the analysis of the subtitling work carried out by four trainee translators with and without the assistance of Wordfast Classic, and the comparison with the subtitling work by professional and amateur translators, we analyze how semi-automation of subtitling can influence on standardizing and expediting the translator's work.
\end{abstract}

